\title{
Neurodegeneration in the HAART era
}

\author{
Bruce J Brew \\ From $16^{\text {th }}$ International Symposium on HIV and Emerging Infectious Diseases \\ Marseille, France. 24-26 March 2010
}

Highly active antiretroviral therapy (HAART) has led to dramatic changes in HIV disease. Patients are now living for a significantly longer time; with increasing numbers over the age of 60 . Most have been living with HIV disease for many years, some in excess of 20 years. Additionally, the number of patients over 50 years old who have recently acquired HIV infection is increasing. Despite the benefits of HAART, cognitive impairment remains. Whilst the incidence of HIV associated dementia (HAD) has significantly fallen with HAART, its prevalence is increasing partly because patients are living longer with fixed deficits. Furthermore, the prevalence of milder cognitive impairment, now termed minor neurocognitive disorder and included under the broader term HIV-associated neurocognitive disorder (HAND), has not changed despite the introduction of HAART. While there are many potential reasons for this, there is concern that the longer duration of HIV disease, as a consequence of HAART, together with the increasing age of infected persons may have a compounding detrimental effect on cognitive function. Additionally, these two factors may facilitate and perhaps enhance the expression of a variety of neurodegenerative diseases as HIV-infected patients approach the age where such disorders become increasingly common. This presentation will review the evidence for the potential compounding effect of age on cognition in HIV disease by examining the evidence for persistent and developing neurodegeneration in HAART treated patients, particularly in those maximal suppression of HIV viral load in the blood and cerebrospinal fluid (CSF). Analysis of three different cohorts has shown an approximate rate of HAND of $35 \%$ in patients with advanced HIV disease who are virally suppressed. Evidence for the facilitation of neurodegenerative diseases by HIV and age, will also be detailed. This primarily centres around evidence for the development of an Alzheimer like illness and

Department of Neurology, Level 4, Xavier Building, St. Vincent's Hospital, Victoria Street, Darlinghurst, Sydney, Australia
Parkinsonism. This is followed by a delineation of the potential mechanisms firstly by a review of the general aspects of the pathogenesis of neurodegenerative diseases. Then the effects of normal ageing and how they intersect with HAND will be discussed, followed by a review of the overlapping features and mechanisms in HIV and neurodegenerative diseases. Lastly two potential therapeutic interventions, the rationale for optimising HAART to ensure adequate brain penetration of antiretroviral drugs, and the clinical value of risk factor reduction for neurodegenerative diseases will be reviewed.

Published: 11 May 2010

doi:10.1186/1742-4690-7-S1-17

Cite this article as: Brew: Neurodegeneration in the HAART era. Retrovirology 2010 7(Suppl 1):17.

Submit your next manuscript to BioMed Central and take full advantage of:

- Convenient online submission

- Thorough peer review

- No space constraints or color figure charges

- Immediate publication on acceptance

- Inclusion in PubMed, CAS, Scopus and Google Scholar

- Research which is freely available for redistribution

Submit your manuscript at www.biomedcentral.com/submit 